\title{
Moisture-sensitive smart hot-melt adhesive from polyamide 6
}

\author{
Masayuki Yamaguchi ${ }^{1}$ (i) $\cdot$ Ryo Takatani ${ }^{1} \cdot$ Yusuke Sato $^{1} \cdot$ Shuichi Maeda ${ }^{2}$
}

Received: 23 March 2020 / Accepted: 20 August 2020 / Published online: 27 August 2020

(c) Springer Nature Switzerland AG 2020

\begin{abstract}
The bonding strength of a hot-melt adhesive composed of polyamide 6 (PA6) and lithium bromide ( $\mathrm{LiBr}$ ) with a metal plate was evaluated. PA6 containing LiBr showed strong lap shear strength with a metal plate immediately after hot-melt adhesion above the melting point of PA6, e.g., 1.0 MPa between $\mathrm{PA} / \mathrm{LiBr}(90 / 10)$ and aluminum plates. Owing to the high adhesive strength, the cohesive failure and/or plastic deformation of PA6 was detected during lap shear strength measurements. In contrast, separation was achieved without any difficulty after moisture absorption with a low strength, e.g., 0.1 MPa between PA6/LiBr (90/10) and aluminum plates. Furthermore, there was no trace of the adhesive on the metal plate after peeling. Therefore, this smart hot-melt adhesive provides an easy-peeling nature only through exposure to humid conditions as a trigger, which can be employed for various applications such as high-performance masking films.
\end{abstract}

Keywords Hot-melt adhesion · Polyamide $6 \cdot$ Lithium salt · Adhesive strength · Smart polymer

\section{Introduction}

The bonding strength of hot-melt adhesives needs to be precisely controlled for all applications. Furthermore, the durability of bonding strength is a critical factor in choosing the appropriate adhesive system in general. However, if bonding strength is controlled by a specific trigger, its applications will be widened greatly. For example, a masking film used to protect a product surface should have a high bonding strength only during transit and be removed from the product without difficulty when the stimulus loses bonding strength. This is a desirable property, especially in the semiconductor industry. A glue comprising a water-based adhesive, such as starch, might be one such example, because the bonding strength becomes weak after immersing in water. However, this technique is not desirable because a clean surface is hard to obtain after separation.

Herein, a new type of a hot-melt adhesive has been proposed that shows high bonding strength with a metal plate under dry conditions. However, after absorbing moisture, this bonding strength is lost without remaining in the bonding area. The adhesive employed in this study was polyamide 6 (PA6) containing lithium bromide (LiBr). Polyamides have long been widely employed as hot-melt adhesives and are known to have high softening temperatures and good adhesive strength, even with metals [1-3].

Recently, we found that adding $\mathrm{LiBr}$ greatly enhanced the glass transition temperature $\left(T_{\mathrm{g}}\right)$ of PA6 $\left(48{ }^{\circ} \mathrm{C}\right.$ for PA6 compared with $130{ }^{\circ} \mathrm{C}$ for PA6 containing $20 \% \mathrm{LiBr}$ ) [4]. Furthermore, the modulus in the glassy region was enhanced. Similar phenomena have been detected also for other polar polymers, which are attributed to the strong ion-dipole interaction between cations and polar functions in polymers such as amide group [5-8]. Moreover, adding $\mathrm{LiBr}$ reduces the crystallinity of PA6, leading to optical transparency. As the intrinsic birefringence is significantly high owing to enhanced polarizing anisotropy, ascribed to ion-dipole interactions [4, 9], the hot-stretched film exhibits a high level of orientation birefringence.

$\triangle$ Masayuki Yamaguchi, m_yama@jaist.ac.jp|'School of Materials Science, Japan Advanced Institute of Science and Technology, 1-1 Asahidai, Nomi, Ishikawa 923-1292, Japan. ${ }^{2}$ Organization of Research Initiatives, Yamaguchi University, 2-16-1 Tokiwadai, Ube, Yamaguchi 755-8611, Japan. 
These phenomena should be noted as a modification method of PA6 for optical applications. However, as shown in the present study, the blends greatly absorb atmospheric moisture owing to the presence of a salt. The absorbed water molecules act as a plasticizer for PA6, decreasing the $T_{\mathrm{g}}$. Furthermore, the enhanced mobility of PA6 chains caused by moisture absorption accelerates crystallization.

In this study, we employed this marked water absorbency to control bonding strength with a metal plate. This material can be classified as a new type of smart hot-melt adhesive, which has the capability to expand the applications of hot-melt adhesives.

\section{Materials and methods}

\subsection{Materials and sample preparation}

Commercially available polyamide 6 (PA6; Ube Nylon $1022 B$, Ube Industries, Japan) was kindly provided by Ube Industries. The melting point is $220^{\circ} \mathrm{C}$, and the numberaverage molecular weight is 22,000 . Lithium bromide ( $\mathrm{LiBr}$; Tokyo Chemical Industry, Japan) was used without further purification.

After drying at $80^{\circ} \mathrm{C}$ for $4 \mathrm{~h}$ under vacuum, PA6 and $\mathrm{LiBr}$ were placed into an internal batch mixer (Labo Plastmill 10M100, Toyo Seiki Seisakusyo, Japan) equipped with counter-rotating twin rotors at $250^{\circ} \mathrm{C}$. The mixing period was $3 \mathrm{~min}$, and the rotation speed was $30 \mathrm{rpm}$. The blend ratios of PA6/LiBr were 100:0, 95:5, and 90:10 by weight. The obtained mixtures were compressed into flat films with a thickness of $300 \mu \mathrm{m}$ at $250{ }^{\circ} \mathrm{C}$ for $2 \mathrm{~min}$ and subsequently quenched at $25^{\circ} \mathrm{C}$. The samples were sandwiched between stainless steel plates with a thickness of $1.5 \mathrm{~mm}$, which were used in the adhesive tests to apply the same cooling conditions as for the laminated samples in adhesive tests, as shown later. A silicone release agent was coated on the surface of the steel plates prior to compression molding to separate the sample films without difficulty.

\subsection{Measurements}

The adhesive strength was evaluated using lap shear tests $[10,11]$. The sample specimens used are shown in Fig. 1. The adhesives, such as pure PA6 and PA6/LiBr, were sandwiched by metal plates, namely, aluminum or stainless steel. The length of the adhesive was $12 \mathrm{~mm}$, and the thickness was around $100 \mu \mathrm{m}$. The metal plates were $100 \mathrm{~mm}$ in length, $20 \mathrm{~mm}$ in width, and $1.5 \mathrm{~mm}$ in thickness. The surface of the metal plates was washed with acetone prior to use. Hot-melt adhesion was performed

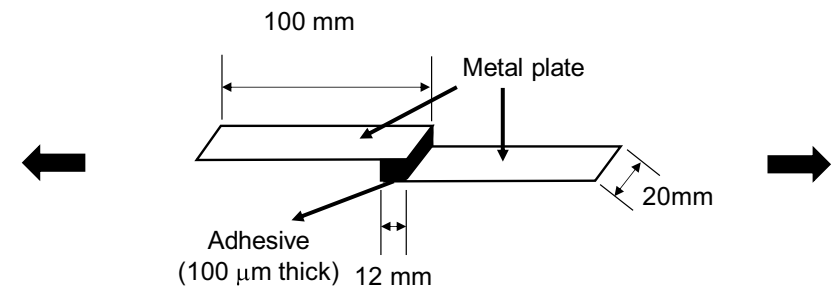

Fig. 1 Illustration of lap shear experiment

at $250{ }^{\circ} \mathrm{C}$ for $2 \mathrm{~min}$ under slight pressure (lower than $0.1 \mathrm{MPa}$ ) to achieve the perfect contact with metal plates, followed by cooling to $25^{\circ} \mathrm{C}$ using another compression molding machine. Since the thermal diffusivities of the metal plates are high enough $\left(1.3 \times 10^{-5} \mathrm{~m}^{2} / \mathrm{s}\right.$ for steel and $8.4 \times 10^{-5} \mathrm{~m}^{2} / \mathrm{s}$ for aluminum), the temperature of the adhesives must be controlled. In fact, it was confirmed that PA6 is in the molten state in $1 \mathrm{~min}$; i.e., the temperature was higher than the melting point $\left(220^{\circ} \mathrm{C}\right)$.

The laminated specimen was clamped in a tensile machine (LSC-50/300, Tokyo Testing Machine, Japan) at $25^{\circ} \mathrm{C}$. One clamp was moved at $10 \mathrm{~mm} / \mathrm{min}$ to measure the lap shear strength. Some specimens were stored in a temperature and humidity-controlled chamber (IG420, Yamato, Japan) at $25^{\circ} \mathrm{C}$ and $50 \%$ relative humidity $(\mathrm{RH})$ before the lap shear tests. Measurements were performed three times, and the average value was calculated.

The steady-state shear viscosity was evaluated at $250^{\circ} \mathrm{C}$ using a capillary rheometer (140SAS, Yasuda Seiki Seisakusyo, Japan) equipped with a circular die of $20 \mathrm{~mm}$ in length and $1 \mathrm{~mm}$ in diameter. The entrance angle was $2 \pi$.

The water contents of the films were measured with a chemical balance using a compression-molded film as a function of the storage period in the temperature and humidity-controlled chamber. Before weight measurements, the film surface was wiped to remove water droplets (if present).

The temperature dependence of the oscillatory tensile modulus at $10 \mathrm{~Hz}$ was evaluated with a rectangular specimen using a dynamic mechanical analyzer (E4000-DVE, UBM, Japan) from 30 to $230^{\circ} \mathrm{C}$ at a heating rate of $2{ }^{\circ} \mathrm{C} /$ $\min$.

The wide-angle X-ray diffraction patterns of films were evaluated by an X-ray diffractometer (SmartLab, Rigaku, Japan) using CuKa radiation operating at $40 \mathrm{kV}$ and $30 \mathrm{~mA}$ with a scanning speed of $0.50 \% \mathrm{~min}$.

Infrared spectra were collected using a Fourier-transform infrared (FT-IR) spectrometer (Spectrum 100, PerkinElmer, MA) at room temperature. Measurements were performed in attenuated total reflection (ATR) mode using KRS-5 as an ATR crystal. 


\section{Results and discussion}

\subsection{Characterization of PA6 containing LiBr}

The viscosity of adhesives is known to be important because it affects their wetting behavior $[10,11]$. Figure 2 shows flow curves, namely, steady-state shear viscosity plotted against shear rate, for the dry samples at $250{ }^{\circ} \mathrm{C}$, which was the bonding temperature. Both shear rate and shear viscosity are the values on the wall of a capillary die. The shear viscosity was found to increase with the addition of $\mathrm{LiBr}$, especially in the low shear rate region, causing the non-Newtonian behavior to become pronounced.

In our previous study, master curves of the oscillatory shear modulus were obtained as a function of frequency [4]. According to the experiments, the zero shear viscosities were $2.5 \times 10^{3} \mathrm{~Pa} \cdot \mathrm{s}$ for PA6 and $2.2 \times 10^{4} \mathrm{~Pa} \cdot \mathrm{s}$ for PA6/ $\mathrm{LiBr}(90 / 10)$ at $230^{\circ} \mathrm{C}$. Furthermore, the flow activation energies were found to be $31 \mathrm{~kJ} / \mathrm{mol}$ for PA6 and $38 \mathrm{~kJ} /$ mol for PA6/LiBr (90/10). Therefore, the zero shear viscosity at $250^{\circ} \mathrm{C}$, i.e., the bonding temperature in this study, can be calculated as follows; $1.9 \times 10^{3} \mathrm{~Pa}$.s for PA6 and $1.6 \times 10^{4} \mathrm{~Pa} \cdot \mathrm{s}$ for $\mathrm{PA} 6 / \mathrm{LiBr}(90 / 10)$.

Figure 3 shows the growth curves for the sample weight under the storage conditions, namely, $25^{\circ} \mathrm{C}$ and $50 \% \mathrm{RH}$. Water absorption increased with an increasing storage period, becoming saturated at around $24 \mathrm{~h}$. The equilibrium water contents were $3.2 \%$ for PA6 and $7.7 \%$ for $\mathrm{PA} 6 / \mathrm{LiBr}(90 / 10)$. Clearly, the equilibrium value

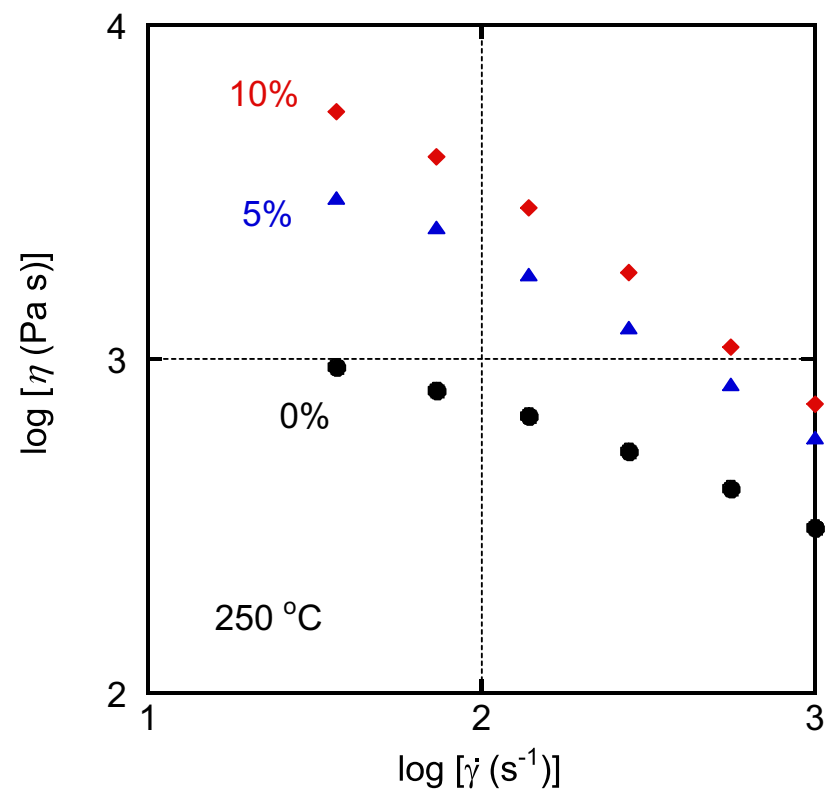

Fig. 2 Shear viscosity plotted against shear rate at $250^{\circ} \mathrm{C}$. Numbers in the figure represent the weight fraction of $\mathrm{LiBr}$

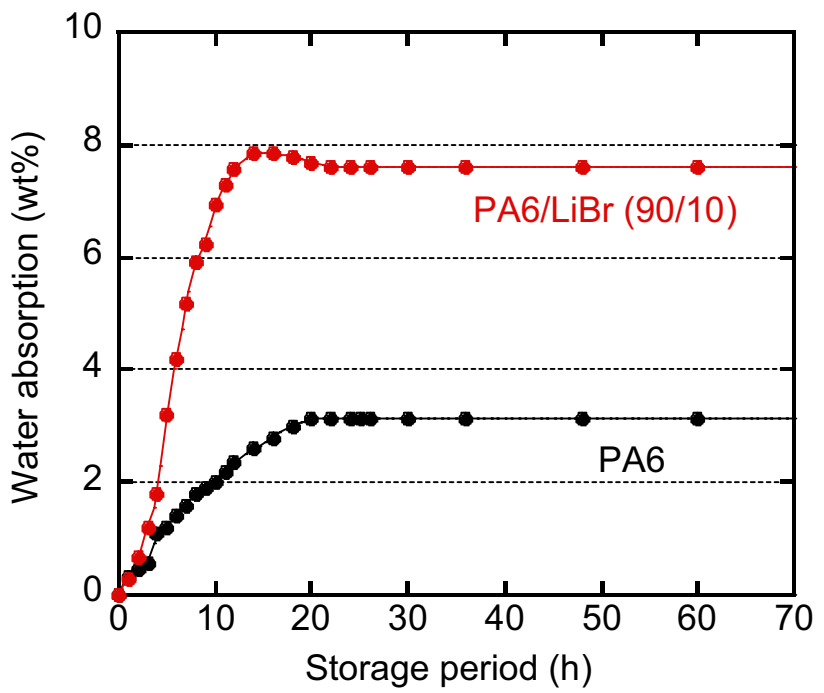

Fig. 3 Growth curves of water absorption as a function of storage period at $25{ }^{\circ} \mathrm{C}$ and $50 \% \mathrm{RH}$ for (closed) PA6 and (open) PA6/LiBr $(90 / 10)$

increased with $\mathrm{LiBr}$ addition. Furthermore, overshooting was detected for $\mathrm{PA} 6 / \mathrm{LiBr}(90 / 10)$. This phenomenon indicates that excess absorbed water was expelled by PA6 crystallization, because water molecules cannot exist in the crystalline region. In fact, water droplets were detected on the film surface beyond the overshooting. Crystallization through water absorption will be discussed in detail below.

Figure 4 shows the temperature dependence of dynamic tensile moduli, such as the storage modulus $\left(E^{\prime}\right)$ and loss modulus $\left(E^{\prime \prime}\right)$, for films of pure PA6 and PA6/ $\mathrm{LiBr}(90 / 10)$. Data for the films after moisture absorption $\left(25^{\circ} \mathrm{C}\right.$ and $50 \% \mathrm{RH}$ for $24 \mathrm{~h}$ ) are denoted as filled symbols in Fig. 4.

For the dry films immediately after compression molding, the peak temperature of $E^{\prime \prime}$, defined as the glass transition temperature $\left(T_{g}\right)$, was found to be $52^{\circ} \mathrm{C}$ for pure PA6 and $90^{\circ} \mathrm{C}$ for $\mathrm{PA} 6 / \mathrm{LiBr}(90 / 10)$. This $T_{\mathrm{g}}$ enhancement corresponds well with previous results and is attributed to ion-dipole interactions with lithium cations [4-9].

Furthermore, adding LiBr decreased the crystallinity of PA6, which resulted in the modulus dropping beyond the $T_{\mathrm{g}}$. After exposure to humid conditions $\left(25^{\circ} \mathrm{C}\right.$ and $\left.50 \% \mathrm{RH}\right)$ for $24 \mathrm{~h}$, the dynamic mechanical properties had changed dramatically due to the hygroscopic character of the salt [12]. Even for the pure PA6 film, the $T_{\mathrm{g}}$ was shifted to a lower temperature, indicating that water molecules acted as a plasticizer, which is a well-known phenomenon [13, 14]. For the $\mathrm{PA6} / \mathrm{LiBr}(90 / 10)$ film, the marked $T_{\mathrm{g}}$ decrease was detected with moisture absorption. Above the $T_{g}$, the moduli were much higher than those of the dry film owing to PA6 crystallization, as described later. As the modulus 


\section{(a) PA6}

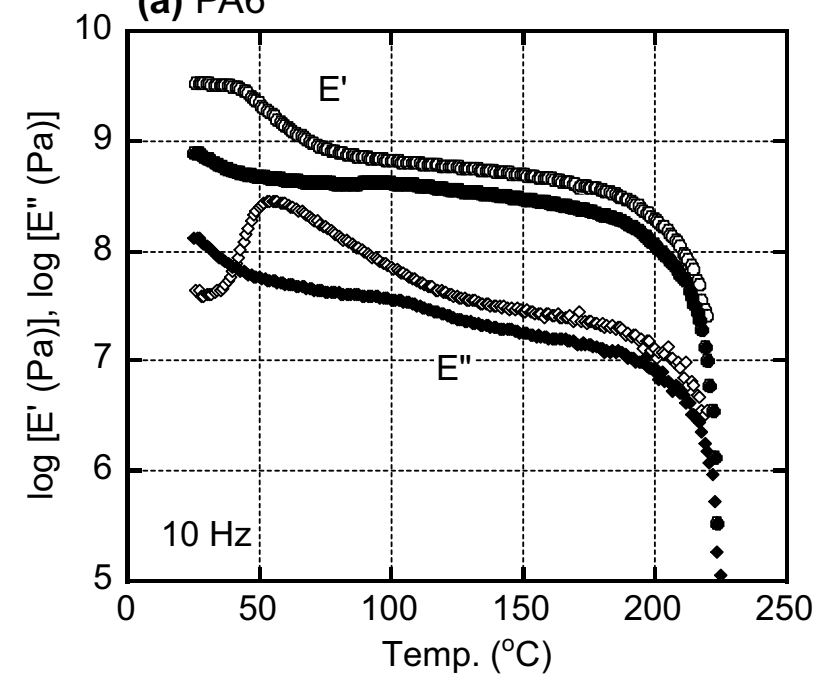

(b) $\mathrm{PA6} / \mathrm{LiBr}(90 / 10)$

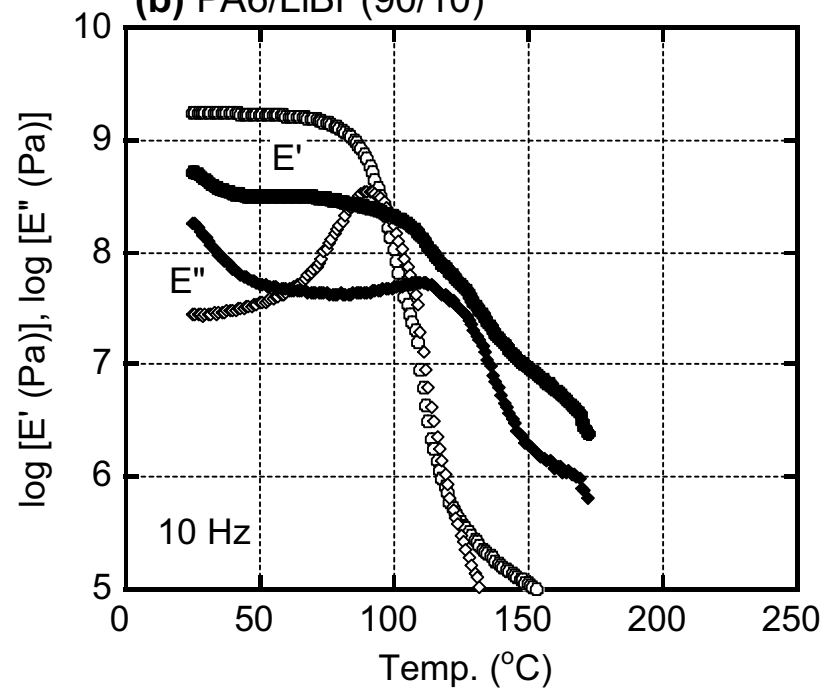

Fig. 4 Temperature dependence of tensile storage modulus $E^{\prime}$ and loss modulus $E^{\prime \prime}$ at $10 \mathrm{~Hz}$ for (open symbols) dry films and (closed symbols) films after moisture absorption: a PA6 and b $\mathrm{PA} 6 / \mathrm{LiBr}$ $(90 / 10)$

decreased gradually, even beyond the $T_{\mathrm{g}}$, the crystallinity seemed to be low.

The effect of moisture absorption on the crystalline structure was studied by WAXD and FT-IR measurements. Figure 5 shows the WAXD profiles for both dry and humid $\left(25^{\circ} \mathrm{C}\right.$ and $50 \% \mathrm{RH}$ for $24 \mathrm{~h}$ ) films. The diffraction peak at a $2 \theta$ value of around $22^{\circ}$ became sharp after moisture absorption, demonstrating that crystallinity was enhanced. This diffraction was known to be ascribed to $\gamma$-form crystals of PA6, which are usually generated by rapid cooling $[15,16]$.

The growth of crystallinity under humid conditions was attributed to water absorption, which leads to the

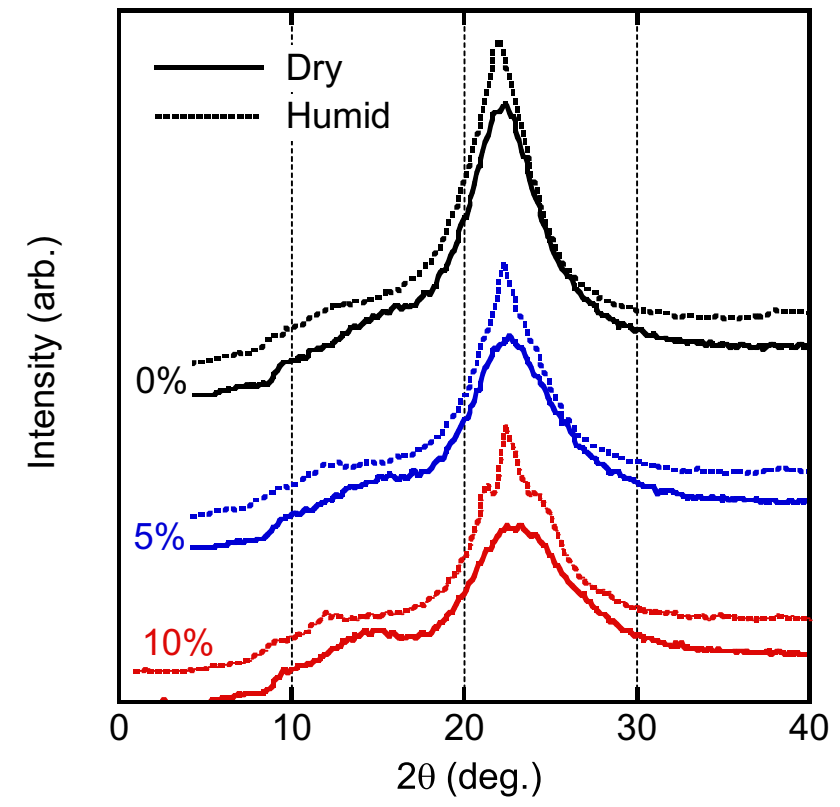

Fig. 5 WAXD profiles for PA6 and PA6/LiBr blends. Numbers in the figure represent the weight fraction of $\mathrm{LiBr}$

plasticization of PA6 chains and, therefore, enhances molecular motion.

The crystalline form can also be confirmed by FT-IR spectra. As shown by the previous study [15], the absorbance at $930 \mathrm{~cm}^{-1}$ is ascribed to the $a$-form crystal, while that at $973 \mathrm{~cm}^{-1}$ is to the $\gamma$-form crystal. Furthermore, the peak at $983 \mathrm{~cm}^{-1}$ is known to be attributed to the amorphous band [15]. According to our previous study [4], LiBr addition reduced the crystallinity of both $a$ - and $\gamma$-form crystals, as shown in Fig. 6a. However, after moisture absorption, both bands at 930 and $973 \mathrm{~cm}^{-1}$ were clearly detected in the films containing $\mathrm{LiBr}$, indicating that crystallization occurs with the aid of water molecules. These results correspond with the WAXD profiles. FT-IR spectra also give information on the hydrogen bonding, with $\mathrm{NH}$ stretching of the hydrogen-bonded $\mathrm{NH}$ group of PA6 appearing at $3300 \mathrm{~cm}^{-1}[17,18]$. As shown in Fig. $6 \mathrm{~b}$, the peak shift provided by $\mathrm{LiBr}$ addition was not detected after moisture absorption. This result demonstrates that the strong ion-dipole interaction with lithium cations disappeared because of the crystallization of PA6, leading to intramolecular hydrogen bonding of PA6, as well as the interaction between lithium cations and water molecules. Consequently, the $T_{\mathrm{g}}$ decreased after moisture absorption through enhanced molecular motion, which is also responsible for the growth of crystallization. 
(a)

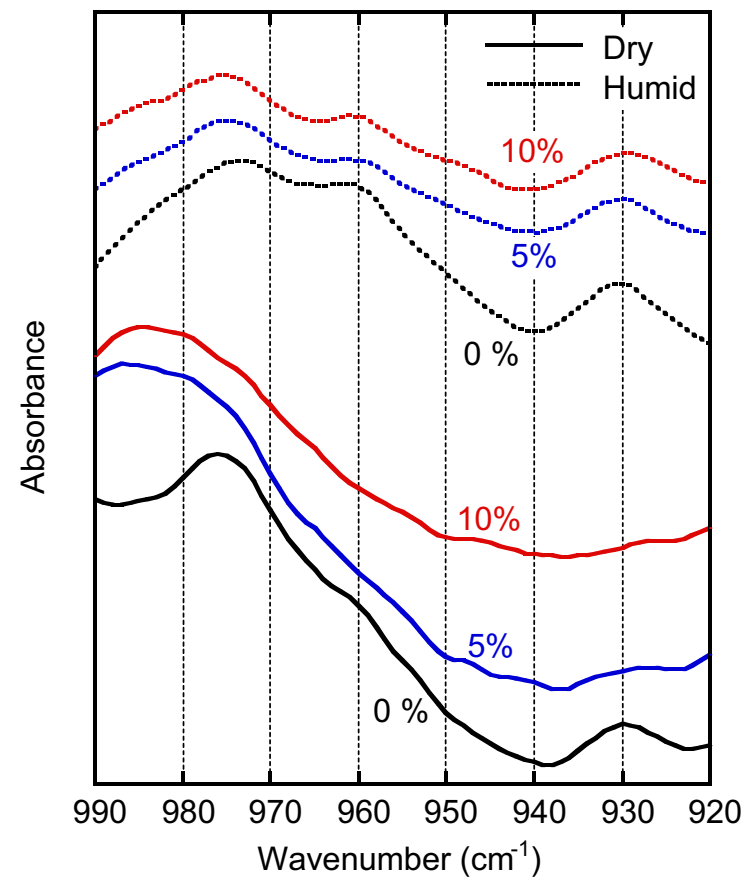

(b)

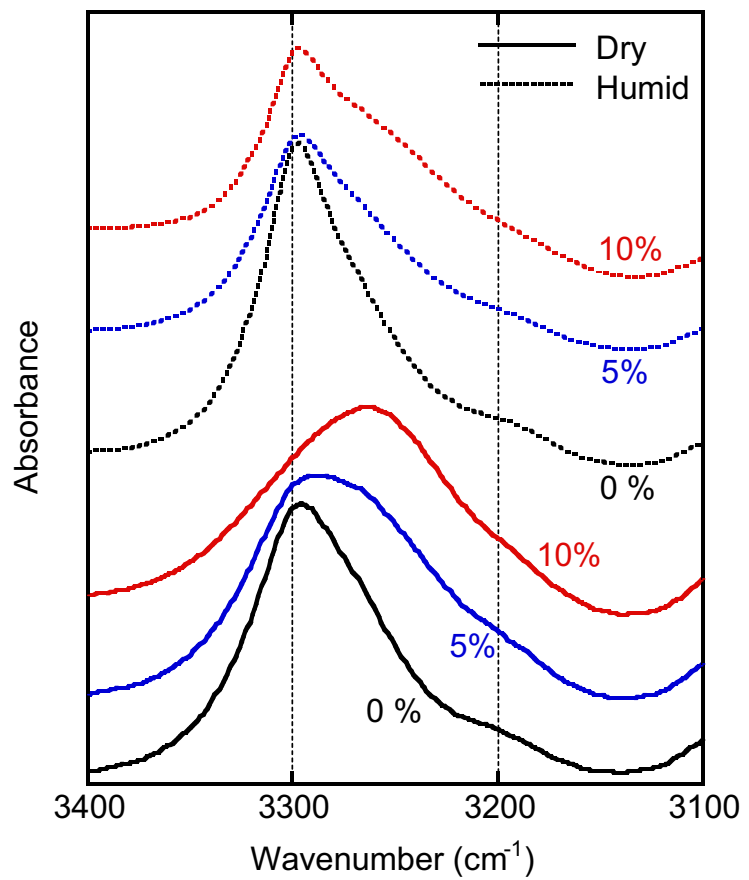

Fig. 6 FT-IR spectra for PA6 and PA6/LiBr blends. Numbers in the figure represent the weight fraction of $\mathrm{LiBr}$

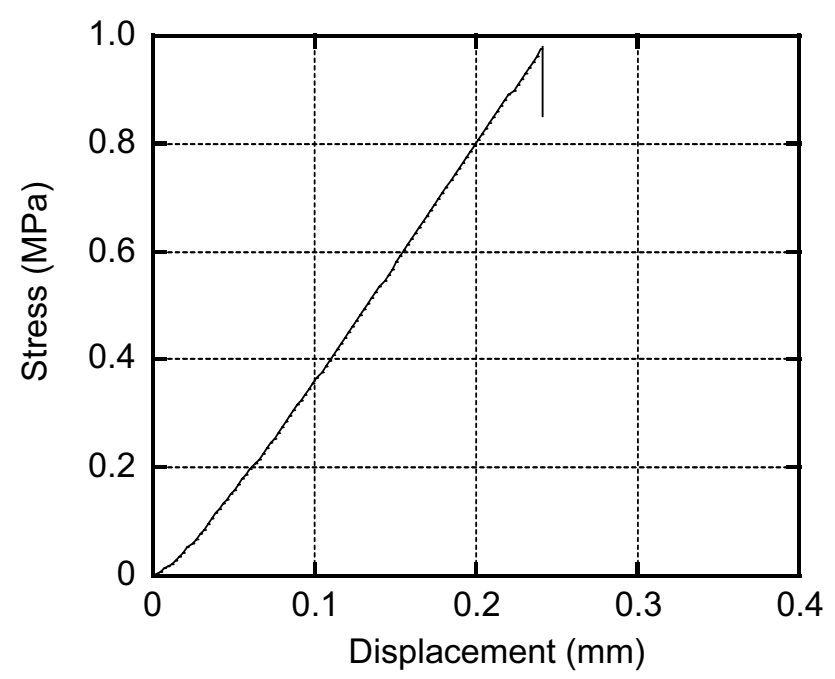

Fig. 7 Example stress-displacement curve for the laminated sample composed of $\mathrm{PA6} / \mathrm{LiBr}(90 / 10)$ and aluminum plates

\subsection{Adhesive strength with metal plates}

The lap shear strengths were measured using the dry and humid samples. Figure 7 shows an example stress-displacement curve of the laminated sample. The stress increased monotonically and dropped abruptly with debonding for all samples. We defined the lap shear strength as the maximum stress at debonding.

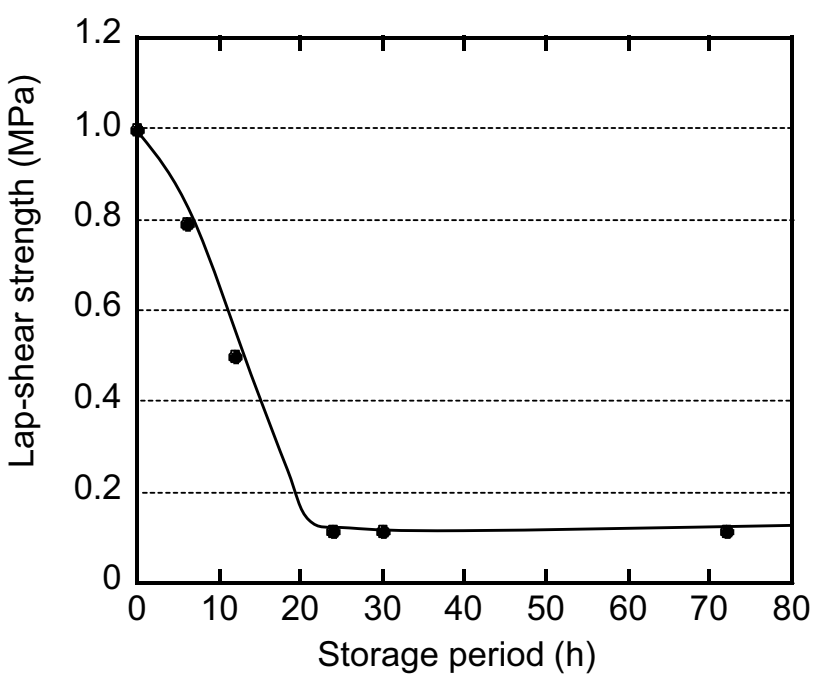

Fig. 8 Relationship between storage period at $25^{\circ} \mathrm{C}$ and $50 \% \mathrm{RH}$ and lap shear strength for the laminated sample composed of PA6/ $\mathrm{LiBr}(90 / 10)$ and aluminum plates

First, we evaluated the lap shear strength with aluminum plates as a function of the storage period in the temperature-and-humidity controlled chamber using PA6/LiBr (90/10), which was the most hygroscopic sample in this study. As shown in Fig. 8, the lap shear strength decreased with increasing storage period, 
becoming a constant value after $24 \mathrm{~h}$, which corresponds to the water absorption curve.

The adhesive strength with metal plates is summarized in Fig. 9. The adhesive strengths of the dry samples, measured immediately after compression molding, were denoted as bars with crossed lines, while those of the humid samples, measured after storage at $25^{\circ} \mathrm{C}$ and $50 \%$ $\mathrm{RH}$ for $24 \mathrm{~h}$, were expressed as filled bars. PA6 showed high adhesive strength with metal plates, which is attributed to the strong dipole-dipole interaction [2,3]. As increasing the $\mathrm{LiBr}$ content, the lap shear strength was found to decrease. This is reasonable because some of amide groups have the interaction with lithium cations not
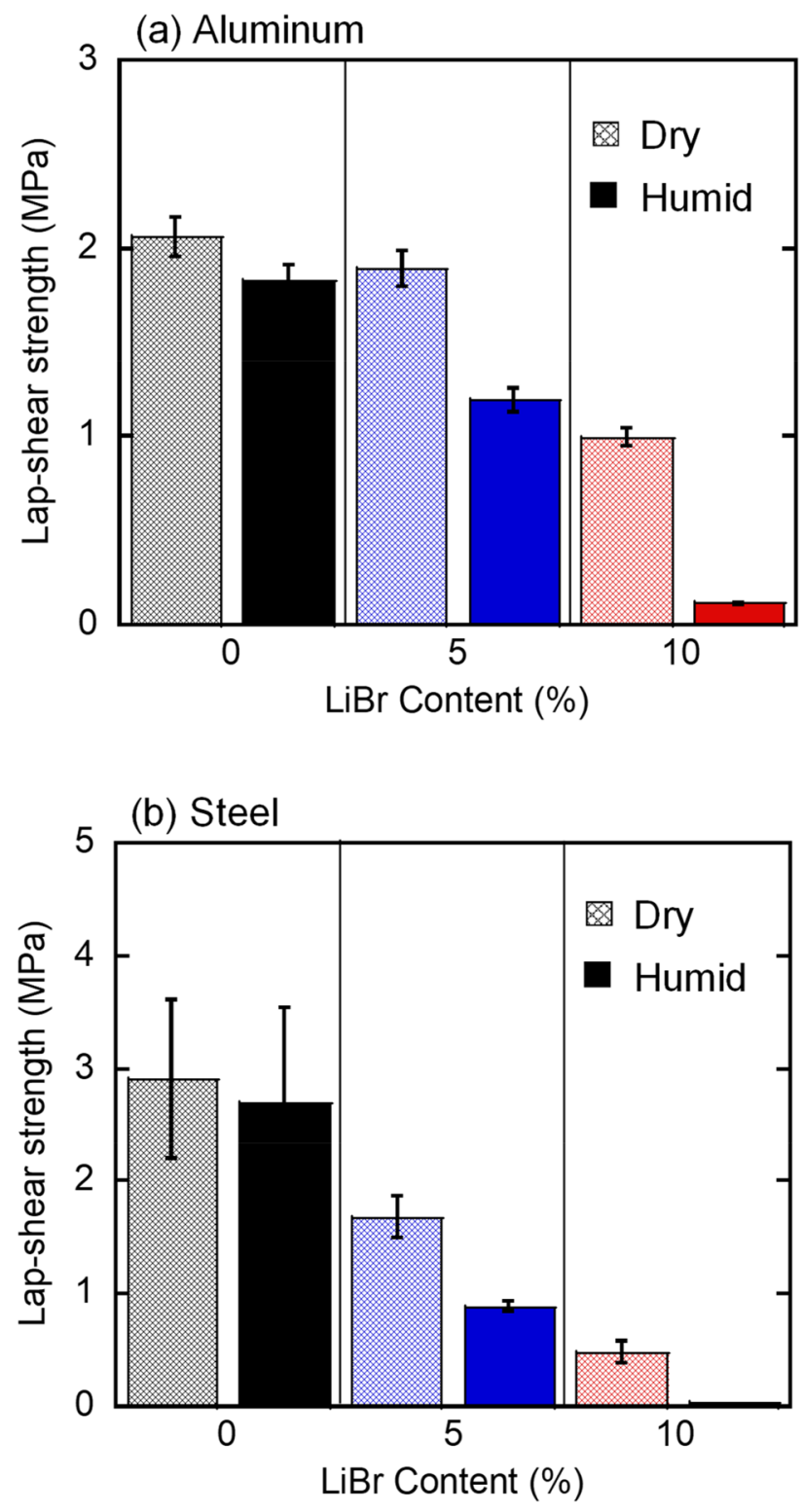

Fig. 9 Lap shear strengths for samples laminated with a aluminum plates and $\mathbf{b}$ steel plates metal plates. Furthermore, the adhesive strength of the samples containing $\mathrm{LiBr}$ was greatly decreased by moisture absorption.

The steel surfaces after the lap shear tests using PA6/ $\mathrm{LiBr}(90 / 10)$ are shown in Fig. 10. Adhesive PA6/LiBr (90/10) was found randomly on the steel surface in the dry samples, suggesting that both cohesive failure and interfacial peeling occurred. In contrast, no adhesive remained on one of the plate surfaces in the humid sample. The difference in the failure mode of $\mathrm{PA6} / \mathrm{LiBr}(90 / 10)$ was also confirmed by SEM images (Fig. 11). Apparently, adhesive $\mathrm{PA} 6 / \mathrm{LiBr}(90 / 10)$ was deformed in the lap shear test of the dry sample. This indicates that plastic deformation of the adhesive occurs to some degree during debonding owing (a)

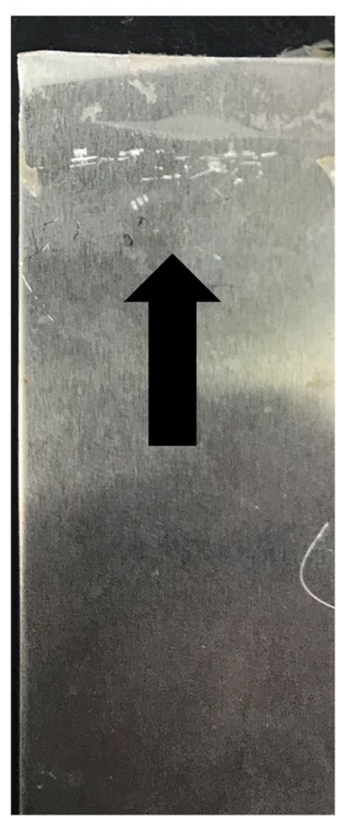

(b)

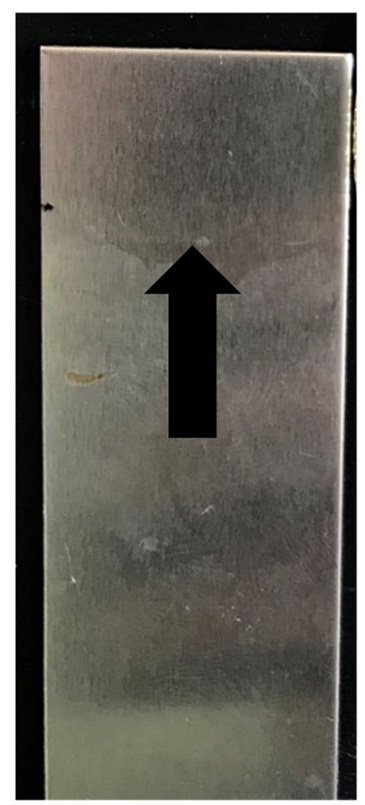

Fig. 10 Surface of steel plates after lap shear tests with $\mathrm{PA} / \mathrm{LiBr}$ (90/10): a Dry and b humid samples. (a)

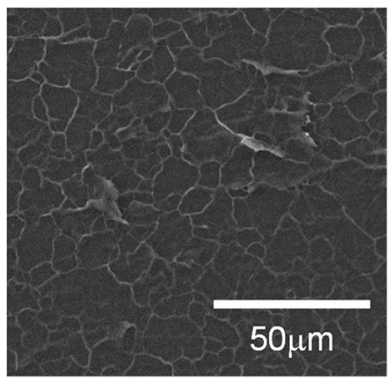

(b)

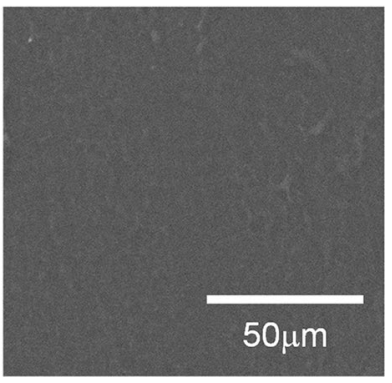

Fig. 11 SEM images of the surface of $\mathrm{PA} / \mathrm{LiBr}(90 / 10)$ films after lap shear tests with steel plates: $\mathbf{a}$ Dry and $\mathbf{b}$ humid samples 
(a)

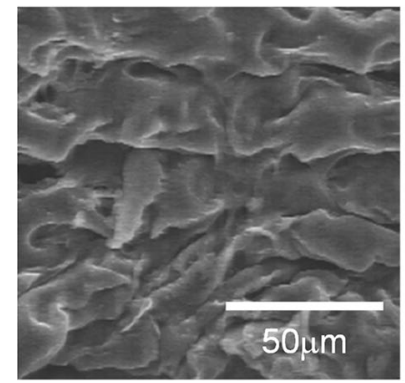

(b)

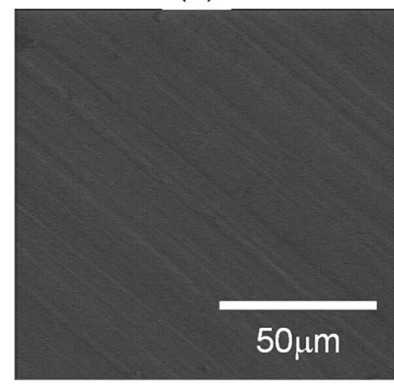

Fig. 12 SEM images of the surface of PA/LiBr (90/10) films after lap shear tests with aluminum plates: $\mathbf{a}$ Dry and $\mathbf{b}$ humid samples

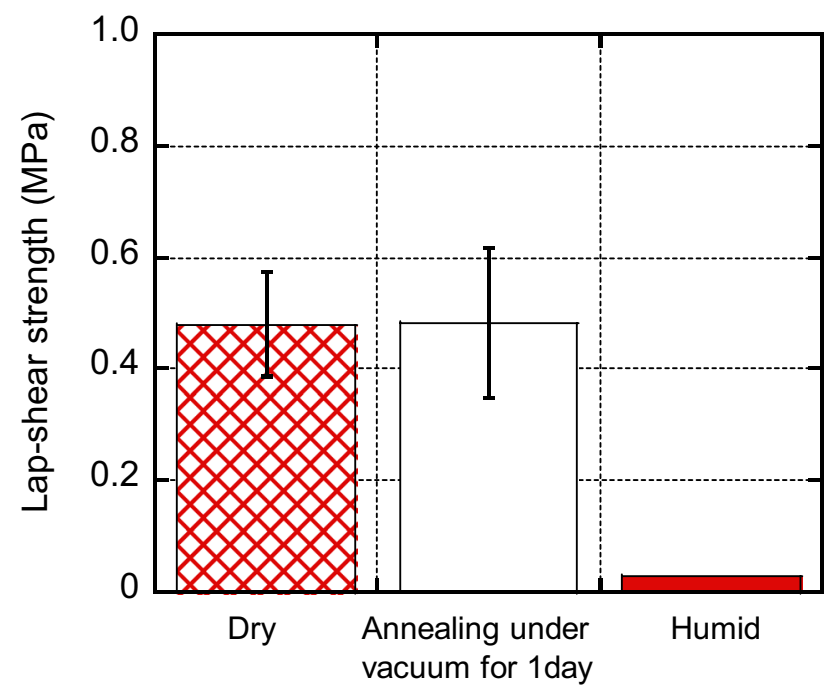

Fig. 13 Lap shear strengths for samples laminated with steel plates

to relatively strong adhesion. In contrast, a smooth surface was detected in the humid sample, demonstrating that separation occurred without any difficulty, with easy peeling at the interface. These results correspond with the lap shear strength. Figure 12 shows the SEM images of the surface separated from the aluminum plate. As the lap shear strength with the aluminum plate was higher than that with the steel plate, the adhesive deformation was more obvious for the dry sample. However, the humid sample showed a smooth surface, indicating easy peeling.

The lap shear strength was further measured after storing the sample under vacuum conditions, rather than humid conditions, at $25^{\circ} \mathrm{C}$ for one day. As shown in Fig. 13, the lap shear strength was not affected by storing the sample under vacuum conditions, indicating that humidity triggered the decrease in adhesive strength.

As shown in Fig. 9, the adhesive strength of the dry samples with a metal plate decreased with increasing $\mathrm{LiBr}$ content. This is attributed to the ion-dipole interactions between lithium cations and amide groups [4], which reduces the interaction between amide groups and metal plates. After moisture absorption, the interaction between amide groups and lithium cations is greatly reduced because the lithium cations have strong interactions with water molecules [12]. Therefore, the crystallization of PA6 is aided by water molecules acting as a plasticizer. During PA6 crystallization, water molecules are expelled from the crystalline region of PA6, resulting in overshooting of the water content as a function of the storage period (Fig. 2). These water molecules are located on the surface of the metal plates, namely, between the metal plate and adhesive, leading to the weak boundary layer $[10,19]$. Furthermore, crystallization enhances the cohesive strength of PA6, which is also responsible for easy peeling at the interface. As a result, the lap shear strength with a metal plate greatly decreases with moisture absorption as the trigger. This smart adhesive has an advantage for masking films because the surface cleaning process is not required, which is different from a glue comprising a water-based adhesive and thus must reduce the total cost. Although only $\mathrm{LiBr}$ was employed as a salt in this study, various salts would be applicable considering the recent works on the salt addition to polar polymers [5-8]. It will be a future work to find an appropriate salt from the viewpoints of the adhesive properties as well as the cost-performance.

\section{Conclusions}

We have investigated the adhesive properties of hotmelt adhesives composed of PA6 and $\mathrm{LiBr}$ with metal plates. The lap shear strengths with metal plates, including aluminum and steel, were found to be high immediately after hot-melt adhesion of PA6/LiBr. Owing to the high bonding strength, the adhesive remained randomly on the metal plates. However, after moisture absorption, at which point the equilibrium water content in the film was greatly enhanced by $\mathrm{LiBr}$ addition, the laminated samples of $\mathrm{PA} 6 / \mathrm{LiBr}$ showed interfacial peeling with a significantly lower lap shear strength. Therefore, exposure to moisture acted as the trigger for easy peeling of the adhesive. This anomalous property will enable this smart hot-melt adhesive to be used in various applications including masking films with a good cost-performance.

Funding A part of this work was funded by a JSPS Grant-in-Aid for Scientific Research (B), Grant Number 16H04201. 


\section{Compliance with ethical standards}

Conflict of interest The authors declare that they have no conflict of interest.

\section{References}

1. Ito B, Fukuda K, Hara R (1987) Metal polyamide adhesive laminates. US Patent 4,690,850

2. Latko-Duralek P, Macutkevic J, Kay C, Boczkowska A, McNally T (2017) Hot-melt adhesives based on co-polyamide and multiwalled carbon nanotubes. J Appl Polym Sci 135:45999

3. Xue W, Zong Z, Zhou L, Zeng Z (2019) Synthesis and properties of nylon 6/66/510 used as hot melt adhesives for metal plate with low-surface-energy coating. J Adh Sci Technol 33:395-405

4. Sato Y, Ito A, Maeda S, Yamaguchi M (2018) Structure and optical properties of transparent polyamide 6 containing lithium bromide. J Polym Sci B Polym Phys 56:1513-1520

5. Miyagawa A, Ayerdurai V, Nobukawa S, Yamaguchi M (2016) Viscoelastic properties of poly(methyl methacrylate) with high glass transition temperature by lithium salt addition. J Polym Sci B Polym Phys 54:2388-2394

6. Sako T, Miyagawa A, Yamaguchi M (2017) Modulus enhancement of polycarbonate by addition of lithium perchlorate. J Appl Polym Sci 134:44882

7. Tomie S, Tsugawa N, Yamaguchi M (2018) Modifying the thermal and mechanical properties of poly(lactic acid) by adding lithium trifluoromethanesulfonate. J Polym Res 25:206

8. Tsugawa N, Ito A, Yamaguchi M (2018) Effect of lithium salt addition on the structure and optical properties of PMMA/PVB blends. Polymer 146:242-248

9. Ito A, Maeno R, Yamaguchi M (2018) Control of optical and mechanical properties of poly(methyl methacrylate) by introducing lithium salt. Opt Mater 83:152-156
10. Wool RP (1994) Polymer interfaces: Structure and strength. Hanser Gardener, Cincinnati, USA

11. Ebnesajjad S, Landrock AH (2015) Adhesins technology handbook, 3rd edn. Elsevier, Amsterdam

12. Ito A, Phulkerd P, Ayerdurai V, Soga M, Courtoux A, Miyagawa A, Yamaguchi M (2018) Enhancement of glass transition temperature for poly (methyl methacrylate) by salt. Polym J 50:857-863

13. Nielsen LE, Landel RF (1994) Mechanical properties of polymers and composites, 2nd edn. CRC Press, Boca Raton

14. Ito A, Ayerdurai V, Miyagawa A, Matsumoto A, Okada H, Courtoux A, Yamaguchi M (2018) Effects of residual solvent on glass transition temperature of poly(methyl methacrylate). J Soc Rheol Jpn 46:117-121

15. Vasanthan N, Salem DR (2001) FTIR spectroscopic characterization of structural changes in polyamide- 6 fibers during annealing and drawing. J Polym Sci B Polym Phys 39:536-547

16. Ramesh C, Gowd EB (2001) High-temperature X-ray diffraction studies on the crystalline transitions in the $a$ - and $\gamma$-forms of nylon-6. Macromolecules 34:3308-3313

17. Socrates $G$ (2001) Infrared and raman characteristic group frequencies, 3rd edn. Wiley, Chichester, pp 143-146

18. Iwamoto R, Murase $H$ (2003) Infrared spectroscopic study of the interactions of Nylon- 6 with water. J Polym Sci B Polym Phys 41:1722-1729

19. Bikerman JJ (1967) Cause of poor adhesion: Weak boundary layers. Ind Eng Chem 59:40-44

Publisher's Note Springer Nature remains neutral with regard to jurisdictional claims in published maps and institutional affiliations. 